\title{
Retraction Note to: Warning of regional landslide disaster based on sensors and the effect of aerobic exercise of obese students
}

\author{
Cixia Zhang ${ }^{1}$
}

Published online: 15 November 2021

(c) Saudi Society for Geosciences 2021

Retraction Note to: Arabian Journal of Geosciences (2021) 14: 1633 https://doi.org/10.1007/s12517-021-08034-x

The Editor-in-Chief and the Publisher have retracted this article because the content of this article is nonsensical. The peer review process was not carried out in accordance with the Publisher's peer review policy. The author has not responded to correspondence regarding this retraction.

The original article can be found online at https://doi.org/10.1007/ s12517-021-08034-x.

Cixia Zhang

zhangcixia87162020@163.com

1 College of Applied Engineering, Henan University of Science and Technology, Sanmenxia 472000, Henan, China 